\title{
As fronteiras entre os cursos de Relações Públicas e Administração de Empresas
}

\author{
The borders between the graduations courses of \\ Public Relations and Business Administration
}

\section{Desire Blum Menezes Torres}

Doutora em Comunicação e Semiótica, Mestre em Administração de Empresas, Especialista em Comunicação Empresarial e Bacharel em Relações Públicas. Professora na Universidade Tuiuti do Paraná (UTP), Curitiba, PR - Brasil, e-mail: desireemenezes@yahoo.com.br

\section{Resumo}

Diversos aspectos contribuem para o escasso conhecimento e a visão distorcida sobre a profissão de relações públicas nas organizações. Fatores históricos, legislação, diretrizes curriculares, estruturas físicas e inexistências e escassez de projetos interligados entre comunicação e os cursos de administração, nas instituições de ensino, expressam os principais motivos desse desconhecimento. Este trabalho tem como objetivo refletir sobre alguns desses fatores, especificamente sobre aspectos, nas instituições de ensino superior, que resultam, de modo mais amplo, no desconhecimento da profissão de relações públicas nas organizações. A metodologia deste artigo consiste em uma pesquisa exploratória, com a utilização dos métodos de coleta de dados bibliográficos e observação indireta em instituições públicas e privadas de ensino de Relações Públicas e Administração de Empresas.

Palavras-chave: Curso de Relações Públicas. Curso de Administração de Empresas. Organização.

\begin{abstract}
Various aspects contribute to poor knowledge and disturb vision about the public relations profession in organizations. Historical factors, legislation, curriculum directions, physical structures, no existences and shortage of interlinked projects between communication and administration courses in educational institutions, express the main reasons for this lack. This work aims to reflect on some of these factors, specifically on aspects, on higher education institutions, which result, more broadly, in breach of the public relations profession in organizations. The methodology of this article is an exploratory research, using the methods of collection of bibliographic data and indirect observations in public and private teaching of Public Relations and Business Administration.
\end{abstract}

Keywords: Course of Public Relations. Course of Business Administration. Organization. 


\section{Introdução}

As organizações representam o campo de atuação para os profissionais de relações públicas (RP) $\mathrm{e}$, na sua grande maioria, são empresas formadas por gestores graduados no curso de Administração de Empresas. Entretanto, muitos desses profissionais não conhecem esse profissional ou têm concepções distorcidas quanto ao que o relações-públicas pode realizar no âmbito das instituições.

Este artigo tem como objetivo geral apontar alguns dos motivos de desconhecimento da profissão de relações públicas entre os profissionais de administração. Os objetivos específicos são:

1) verificar as afinidades entre as áreas;

2) identificar as barreiras entre os acadêmicos de Relações Públicas e de Administração;

3) refletir sobre a conexão entre esses distanciamentos na academia e a dificuldade de ingresso dos relações-públicas nas organizações.

\section{Metodologia}

A escolha metodológica se deu quanto ao tipo de pesquisa-exploratória, tendo como propósito contribuir na formulação de um problema, no sentido de "refinar conceitos, enunciar questões e hipóteses para investigações subseqüentes" (DENCKER;DA VIÁ, 2001, p. 59). Quanto ao método, optou-se pela coleta de dados bibliográficos e pela observação indireta em instituições de ensino de Relações Públicas e Administração de Empresas.

Os autores escolhidos para os apontamentos teóricos consistem em pesquisadores na área de Relações Públicas, sendo eles: Candido Teobaldo de Andrade; James Gruning, Claudia Peixoto de Moura, Margarida K. Kunsch e Jorge Pedro Sousa.

$\mathrm{Na}$ coleta de dados, a observação foi realizada de forma indireta, no período que a pesquisadora atuou como docente nos cursos de Relações Públicas e Administração, entre os anos de 2006 e 2009, em três instituições, duas públicas e uma particular: Universidade Estadual de Londrina (UEL), em 2006, no curso de Relações Públicas; Universidade Federal do Paraná (UFPR) em 2008 e 2009, no curso de Relações Públicas; e na Pontifícia Universidade
Católica do Paraná (PUCPR), de 2007 a 2009, no curso de Administração de Empresas.

Em todas as instituições citadas existem ambos os cursos - Relações Públicas e Administração -, e nesses cenários foram realizados os apontamentos comparativos referentes às dificuldades que os profissionais de relações públicas encontram para atuar nas organizações, bem como a estrutura teórica escolhida para compor as análises. Todos esses fatores contribuíram para compor esses apontamentos.

Em todas as instituições de ensino pesquisadas - UEL, UFPR e PUCPR -, pôde-se constatar que esses cursos estão fisicamente separados, em blocos distintos e, no caso da UFPR, separados em campi específicos, situados em bairros diferentes (Jardim Botânico e Juvevê), com vários bairros entre eles.

Além desses distanciamentos físicos, de blocos e campi, há uma grande separação em virtude das áreas pertencerem a centros diferentes. $\mathrm{Na}$ UEL, o curso de Administração de Empresas está no Centro de Estudos Sociais Aplicados (Cesa) e o de Relações Públicas no Centro de Educação, Comunicação e Artes (Ceca). Na PUCPR, o curso de Administração de Empresas fica no Centro de Ciências Sociais Aplicadas (CCSA) e o curso de Relações Públicas vinculado ao Centro de Ciências Jurídicas e Sociais (CCJS). Já na UFPR, o curso de Administração de Empresas situa-se no Setor de Ciências Sociais Aplicadas e o de Relações Públicas no Setor de Ciências Humanas, Letras e Artes (UEL, 2010a, b; UFPR, 2010; PUCPR, 2010).

Constata-se que as separações entre os Centros e Setores, assim como as distâncias físicas, são frutos da constituição história e ideológica de cada curso. Entretanto, em virtude das intrínsecas relações desses cursos com as organizações, seria bem mais coerente que os estudantes de Administração de Empresas e de Relações Públicas convivessem no período universitário, no sentido das áreas passarem a ter afinidades, para que no futuro os gestores administrativos integrassem os profissionais de relações públicas nas organizações.

\section{Necessidades de relações públicas nas organizações}

A profissão de relações públicas tem como base o "gerenciamento do comportamento da comunicação de uma organização com os seus públicos" 
(GRUNIG; FERRARIA; FRANÇA, 2009, p. 28). Diversos fatores justificam a atuação do profissional nas organizações: credibilidade, relacionamento, satisfação, reputação, economia, entre outros.

As organizações necessitam das relações públicas porque mantêm relacionamentos com públicos. As organizações têm sucesso quando alcançam suas missões e objetivos, e a maioria delas prefere escolher as suas próprias missões e estabelecer os seus próprios objetivos. Raramente, entretanto, podem fazê-lo sozinhas. Os públicos também têm interesses nas organizações e podem, assim, empenhar-se para influenciar as missões e os objetivos dessas organizações (GRUNIG, 2009, p. 27).

Conforme destaca Grunig (2009,p. 27), nem sempre os relacionamentos das organizações com os seus públicos são amigáveis, mas "o entendimento é um objetivo primordial das relações públicas na sua atuação. Uma das formas de medir e compreender esses desentendimentos é verificar a imagem da instituição perante esses públicos. Segundo Sousa (2003, p. 36), "a imagem de uma entidade corresponde àquilo que os públicos pensam que a organização é (ou ainda à forma como uma organização se vê a si mesma)", sendo a comunicação nas organizações responsável em transmitir seus atributos, valores e produtos, bem como captar as percepções e manifestações dos seus públicos. Nesse sentido, uma das formas com que o relações-públicas atua é na realização de auditoria de comunicação, instrumento que permite, segundo esse autor, "recolher dados quer para a melhorar a eficácia e a eficiência organizacionais quer para avaliar as políticas de imagem (se existentes) e a imagem real da entidade" (SOUSA, 2003, p. 41).

Kunsch (2003, p. 103) também comenta sobre a necessidade dos profissionais de relações públicas demonstrarem sua contribuição também econômica para as organizações:

consequentemente, a comunicação e a colaboração geram benefícios para uma organização ao permitir a venda de seus produtos e serviços a clientes satisfeitos, garantir investimentos ou expandir seu âmbito de atuação. Também economizam o dinheiro que as organizações teriam de gastar com processos, regulamentações, boicotes ou treinamentos de novos colaboradores, e reduzem também os riscos de que os públicos afetados iniciem ações dessa natureza (GRUNIG, 2009, p. 28).

Acrescenta-se que "as Relações Públicas criam valor para uma organização porque contribuem para o equilíbrio entre os interesses da própria organização e os interesses das pessoas que são influenciadas por elas" (GRUNIG, 2009, p. 19-20) - fato que reforça a necessidade dessa habilidade de comunicação nas organizações.

\section{As funções essenciais de relações públicas}

A profissão de relações públicas pode ser definida como o exercício de administrar a comunicação nas organizações, mediante o relacionamento com os seus públicos. Os profissionais dessa área possuem como objeto de trabalho as organizações e os seus públicos. Os desafios para a área são de gerenciar a comunicação nas organizações, em meio à complexidade da sociedade contemporânea, e de "contribuir para o cumprimento dos objetivos globais e da responsabilidade social das organizações, mediante o desempenho de funções e atividades específicas" (KUNSCH, 2003, p. 90).

Ainda, segundo Kunsch (2003), as funções essenciais de relações públicas são classificadas em quatro áreas: administrativa, estratégica, mediadora e política. Trata-se de funções que expressam a relação dessa profissão com as organizações. $\mathrm{Na}$ função administrativa, segundo Simon (apud KUNSCH, 2003 , p. 101), avaliam-se "as atitudes dos públicos, identifica[ndo] as políticas e os procedimentos de uma organização com o interesse público e executa[ndo] um programa de ação e comunicação para obter a compreensão e aceitação do público".

Para exercer a função estratégica deve-se buscar a base na pesquisa e no planejamento, no sentido de encontrar as "melhores estratégias comunicacionais para prever e enfrentar as reações dos públicos e da opinião pública em relação às organizações, dentro da dinâmica social" (KUNSCH, 2003, p. 104). Por outro lado,

a função estratégica significa ajudar as organizações a se posicionarperante a sociedade, demonstrando qual a razão de serdo seu empreendimento, 
isto é, sua missão, quais são os seus valores, no que acreditam e o que cultivam, bem como a definir uma identidade própria e como querem ser vistas no futuro (KUNSCH, 2003, p. 103).

A função mediadora corresponde à interação entre as organizações e os seus diferentes públicos, com a utilização de meios de comunicação adequados, propiciando, assim, além de informação, o diálogo, ou seja, a comunicação bilateral. Segundo Kunsch (2003, p. 108), "em sua função mediadora, as relações públicas têm a responsabilidade de fazer a leitura do ambiente, por meio de uma auditoria social, intermediando as relações das organizações com a sociedade".

A função política de relações públicas diz respeito ao profissional conhecer e lidar com as relações de poder, dentro e fora da organização, e com questões ligadas a controvérsias, confrontações, crises e conflitos sociais (KUNSCH, 2003). Com base nas funções essenciais de relações públicas, pode-se verificar a grande necessidade dos profissionais dessa área conhecerem, por diversos ângulos, - para a sua atuação - as organizações.

É grande, no entanto, o desconhecimento por parte de muitos gestores, com formação em Administração, que ocupam os mais variados cargos de alta direção, recursos humanos, e são responsáveis por contratações, mas enfrentam dificuldades em indicar o profissional de relações públicas por não conhecerem suas funções e contribuições que agregam e contribuem nas organizações. Desse modo, pergunta-se: caso não conheçam ou mesmo tenham a visão da função dessa área reduzida ou distorcida, de que forma esses gestores possibilitarão o trabalho em relações públicas? Ou mesmo de que modo darão abertura para a entrada e permanência nas organizações? Dessa forma, ressaltam-se tais fatos como uma das grandes dificuldades para a atuação dos profissionais de relações públicas no mercado de trabalho.

\section{Curso de Relações Públicas - um recorte histórico}

Recorrendo à origem e formação do curso de Relações Públicas no Brasil, é possível analisar sua relação com a área de Administração de Empresas, bem como os esforços que foram realizados para que as áreas se tornassem próximas.
Andrade (1983, p. 157) relata um fato marcante na origem do curso de Relações Públicas no Brasil e na sua ligação com a área de Administração desde seus primórdios. Segundo o autor, o curso de Relações Públicas da então Escola de Comunicações Culturais funcionou com currículo próprio em seus dois primeiros anos de existência, para, em 1969, obedecer ao Parecer n. 890, de 18 de dezembro de 1968, do Conselho Federal de Educação. O curso de Comunicação Social, com a habilitação em Relações Públicas, foi instituído com a Resolução n. 11/69, obrigando essa habilitação a se vincular à área de Comunicação, em conjunto com Jornalismo e Publicidade.

Esses fatos, segundo Andrade (1983, p. 157), contrariavam "a tendência firmada pelo Parecer $n^{\circ} .890 / 68$, que destacava as disciplinas de Administração para a formação do profissional de Relações Públicas". Para Moura (2008), a afinidade do curso de Relações Públicas com o de Administração está presente desde a sua origem.

Pesquisadores da área atestam que a criação da legislação do exercício de relações públicas foi precipitada (ANDRADE, 1983, p. 157). Tal legislação foi criada durante o regime militar e influenciada por interesses desse sistema e a falta de amadurecimento naárea, fatores esses que promoveram - fato compatível com a realidade do País - uma lei deficitária, a Lei n. 5.373 de 1967, regulamentada pelo Decreto n. 63.283 de 1968. Segundo Andrade (1983,p. 158), um fato a ser considerado é que até 1968 os profissionais dessa área "se registravam nos Conselhos Regionais dos Técnicos de Administração para a formação do profissional de Relações Públicas".

No ano de 1977, houve uma solicitação para transferir a habilitação de Relações Públicas do curso de Comunicação Social para o de Administração. Segundo Moura (2008), duas entidades estavam envolvidas nessa sugestão: o Conselho Federal de Profissionais de Relações Públicas (Conferp) e a Assessoria do Departamento de Assuntos Universitários (DAU), da área da Comunicação Social. Entretanto, tal sugestão foi recusada em razão da "grande diversidade entre o campo de ação e as atribuições específicas de cada um desses profissionais", segundo o texto do Parecer n. 02/78 (apud MOURA, 2008, p. 690-691).

Assim, ficou estabelecido que a área de Relações Públicas, na Resolução de n. 3/78, segundo Andrade (1983, p. 158), fixou: 
o currículo mínimo de Comunicação Social, permitiu que a questão Administração ou Comunicação no ensino de Relações Públicas de certa forma fosse superada. Embora as Relações Públicas continuassem em Comunicação Social, as matérias de natureza profissional previstas abriam campo para o ensino de disciplinas da área de Administração, o que foi feito por várias escolas.

Tal indicação, segundo Moura, manteve-se no currículo mínimo estabelecido em 1984, e continua atualmente, segundo as diretrizes curriculares propostas pelo MEC, reforçando que "os cursos de Comunicação Social, com habilitação em Relações Públicas, vão continuar oferecendo conteúdos gerais e específicos da área de Administração" (MOURA, 2008, p. 691).

Para Kunsch (2003), os fundamentos e os pressupostos teóricos para a prática das relações públicas têm se baseado nas ciências sociais aplicadas, haja vista que a Comunicação e as Relações Públicas estão integradas, segundo agências financiadoras de pesquisa, como: CNPq, Capes e Fapesp.

São bastante relevantes as matérias gerais e específicas de Administração no curso de Relações Públicas, possibilitando o seu conhecimento e a aplicação das suas habilidades e competências nas organizações. Contudo, os administradores conhecem essas áreas? Evidencia-se que o grande gargalo tem sido na fase em que os acadêmicos de Administração só visualizam o campo de relações públicas de forma muito específica, dentro da disciplina de Marketing e na área de Promoção, conforme vasta bibliografia mercadológica, difundida principalmente pelo autor norte americano Philip Kotler. Além disso, outras nomenclaturas criadas pela área mercadológica, que dizem respeito a trabalhos já desempenhados pelos relações-públicas na relação com os seus diversos públicos, foram transportadas com nomes ligados para a área mercadológica: endomarketing; marketing de relacionamento; marketing institucional; e marketing social são alguns exemplos.

Afirma-se, neste estudo, que o conhecimento dos gestores de administração sobre a profissão de RP não está sendo suprida somente com as diretrizes curriculares dessa habilitação. Ou seja, o problema é sistêmico, envolvendo o entorno do curso de Relações Públicas na própria academia, no caso com a falta de relacionamento entre as áreas de
Relações Públicas e Administração em uma das suas fases embrionárias, na formação acadêmica.

\section{Aproximação física e projetos entre as áreas}

As relações que acontecem em um centro universitário ganham maior percepção e são mais conhecidas entre os cursos que integram esse local. A aproximação fisicamente sinaliza que há algo em comum, como também aspectos de participação e afinidade entre as áreas.

Seguindo a organização das áreas: Ciências Aplicadas - que pertencem à Administração; e Ciências Humanas - que estão inseridas no curso de Relações Públicas, as edificações em instituições de ensino que possuem essas formações, em geral, ficam separadas fisicamente, como, por exemplo, na Universidade Estadual de Londrina e na Universidade Federal do Paraná, assim como na Pontifícia Universidade Católica do Paraná. Em algumas, como a UFPR, esses cursos são separados em campi distintos.

Além desse distanciamento, outro mais severo pode ser a falta de projetos em comum entre essas áreas nas instituições de ensino, fato que foi observado entre as instituições citadas, com a ausência de atividades em comum.

Acredita-se que os vieses existentes em conceitos distorcidos e reducionistas do papel dos profissionais de relações públicas nas organizações, em publicações destinadas à área do curso de administração, somados aos fatores apontados de falta de interação física e de projetos entre as áreas, resultem no forte desconhecimento por parte dos futuros gestores do curso de Administração e, consequentemente, em uma escassez ou limitação da atuação dos profissionais de relações públicas nas organizações.

\section{Considerações finais}

Apesar de a profissão de relações públicas existir no Brasil desde o início do século XX e ter sido regulamentada em 1968, ainda enfrenta grandes obstáculos na primeira década do século XXI. Isso ocorre em virtude da visão reduzida e distorcida dos acadêmicos de Administração, sobre a profissão de relações públicas, somada ao distanciamento descrito 
pela história dessa área; por fatores físicos nas universidades; e pela falta de projetos em comum entre as áreas nas instituições. Esses dados são indicadores que apontam o desconhecimento dessa profissão entre os gestores de administração e, consequentemente, as dificuldades tanto no seu egresso como em assumir essa profissão não somente nas suas funções técnicas, mas também de exercer suas funções essenciais.

Além dos esforços realizados pelos profissionais e pesquisadores, para o desenvolvimento e fortalecimento do curso de Relações Públicas desde a sua existência no Brasil, somando-se a todo esse contexto torna-se extremamente necessário e emergencial que essa área reflita sobre essas barreiras e que busque alinhar a profissão com a área de Administração ainda nas universidades, tanto na aproximação física como na criação de projetos interligados, no sentido de influenciar novas gerações de administradores para que se tornem conhecedores $\mathrm{e}$, dessa forma, venham a valorizar e a reconhecer a profissão de relações públicas como necessária nas organizações.

\section{Referências}

ANDRADE, C.T. de. Para entender relações públicas. São Paulo: Loyola, 1983.

DENCKER, A. de F. M.; DA VIÁ, S. C. Pesquisa empírica em ciências humanas (com ênfase em comunicação). São Paulo: Futura, 2001.

GRUNIG, J. E.; FERRARIA, M. A.; FRANÇA, F. Relações públicas: teoria, contexto e relacionamentos. São Caetano: Difusão, 2009.

MOURA, C. P. de. (Org.). História das relações públicas: fragmentos da memória de uma área. Porto Alegre: EDIPUCRS, 2008.

KUNSCH, M. K. Planejamento de relações públicas na comunicação integrada. São Paulo: Summus, 2003.

PONTIFÍCIA UNIVERSIDADE CATÓLICA DO PARANÁ - PUCPR. Centros. 2010. Disponível em: <http://www.pucpr.br/institucional/centros.php $>$. Acesso em: 27 set. 2010.

SOUSA, J. P. Planejamento da comunicação na perspectiva das relações públicas. Porto: Universidade Fernando Pessoa, 2003.
UNIVERSIDADE ESTADUAL DE LONDRINA UEL. Administração. 2010a. Disponível em: < http:/ / www2.uel.br/cesa/cesa/administracao.htm>. Acesso em: 27 set. 2010 .

UNIVERSIDADE ESTADUAL DE LONDRINA UEL. Centro de Educação, Comunicação e Artes. 2010b. Disponível em: <http://www.uel.br/ceca>. Acesso em: 27 set. 2010.

UNIVERSIDADE FEDERAL DO PARANÁ UFPR. Sistema de Administração do Website da Universidade Federal do Paraná. 2010. Disponível em: <http://www.ufpr.br/adm>. Acesso em: 27 set. 2010.

Recebido: 13/09/2010

Received: 09/13/2010

Aprovado: 15/09/2010

Approved: 09/15/2010 